\title{
Are we overestimating the loss of beta cells in type 2 diabetes?
}

\author{
Lorella Marselli • Mara Suleiman • Matilde Masini • Daniela Campani • Marco Bugliani • \\ Farooq Syed • Luisa Martino • Daniele Focosi • Fabrizio Scatena • Francesco Olimpico • \\ Franco Filipponi • Pellegrino Masiello • Ugo Boggi • Piero Marchetti
}

Received: 17 May 2013 / Accepted: 9 October 2013 /Published online: 15 November 2013

(C) Springer-Verlag Berlin Heidelberg 2013

\begin{abstract}
Aims/hypothesis Previous work has demonstrated that beta cell amount (whether measured as beta cell mass, beta cell volume or insulin-positive area) is decreased in type 2 diabetes; however, recent findings suggest that mechanisms other than death may contribute to beta cell failure in this disease. To better characterise beta cell mass and function in type 2 diabetes, we performed morphological, ultra-structural and functional studies using histological samples and isolated islets.

Methods Pancreases from ten non-diabetic (ND) and ten matched type 2 diabetic organ donors were studied by insulin, glucagon and chromogranin A immunocytochemistry and electron microscopy (EM). Glucose-stimulated insulin secretion was assessed using isolated islets and studies were performed using independent ND islet preparations after $24 \mathrm{~h}$ exposure to $22.2 \mathrm{mmol} / \mathrm{l}$ glucose.

Results Immunocytochemistry showed that the fractional islet insulin-positive area was lower in type 2 diabetic islets
\end{abstract}

Electronic supplementary material The online version of this article (doi:10.1007/s00125-013-3098-3) contains peer-reviewed but unedited supplementary material, which is available to authorised users.

L. Marselli $\cdot$ M. Suleiman · M. Bugliani $\cdot$ F. Syed $\cdot$ F. Olimpico $\cdot$

P. Marchetti $(\bowtie)$

Department of Clinical and Experimental Medicine, Islet Cell

Laboratory, University of Pisa - Cisanello Hospital,

Via Paradisa 2, 56124 Pisa, Italy

e-mail: piero.marchetti@med.unipi.it

M. Masini • D. Campani · L. Martino • P. Masiello • U. Boggi Department of Translational Medicine, University of Pisa, Pisa, Italy

D. Focosi $\cdot$ F. Scatena

Immunohaematology Center, Cisanello Hospital, AOUP, Pisa, Italy

F. Filipponi

Department of Surgical, Medical and Molecular Pathology,

University of Pisa, Pisa, Italy
$(54.9 \pm 6.3 \%$ vs $72.1 \pm 8.7 \%, p<0.01)$, whereas glucagon $(23.3 \pm 5.4 \%$ vs $20.2 \pm 5.3 \%)$ and chromogranin A $(86.4 \pm 6.1 \%$ vs $89.0 \pm 5.5 \%)$ staining was similar between the two groups. EM showed that the proportion of beta cells in type 2 diabetic islets was only marginally decreased; marked beta cell degranulation was found in diabetic beta cells; these findings were all reproduced after exposing isolated ND islets to high glucose. Glucose-stimulated insulin secretion was $40-50 \%$ lower from type 2 diabetic islets $(p<0.01)$, which again was mimicked by culturing non-diabetic islets in high glucose.

Conclusions/interpretation These results suggest that, at least in subgroups of type 2 diabetic patients, the loss of beta cells as assessed so far might be overestimated, possibly due to changes in beta cell phenotype other than death, also contributing to beta cell failure in type 2 diabetes.

Keywords Beta cells · Chromogranin A · Electron microscopy $\cdot$ Glucagon $\cdot$ Insulin $\cdot$ Insulin granules

\section{Abbreviation \\ EM Electron microscopy}

\section{Introduction}

Decreased beta cell functional mass is a hallmark of type 2 diabetes $[1,2]$. Studies with pancreatic samples obtained at autopsy, from organ donors or after pancreatectomy have shown that beta cell mass is significantly reduced in type 2 diabetic individuals [2-6]. However, beta cell functional defects also play a major role in the pathophysiology of the disease [7], and improvements at this level may better explain, for instance, why $30-100 \%$ of patients who have undergone bariatric surgery may show diabetes remission within a few days after surgery and only a $1-2 \%$ weight loss [8]. In addition, 
recent work has shown that beta cell dedifferentiation may also contribute to beta cell failure in type 2 diabetes [9]. We therefore hypothesised that beta cell loss may be overestimated in type 2 diabetes, and performed morphological, morphometric, ultrastructural and functional studies with pancreatic tissue samples and isolated islets from non-diabetic and type 2 diabetic individuals to explore this possibility.

\section{Methods}

Cases Pancreases were obtained from heart-beating organ donors and handled with the approval of the local ethics committee. Pancreases were from ten non-diabetic (age: $68 \pm 4$ years; sex: five men, five women; BMI: $26.3 \pm 1.6 \mathrm{~kg} / \mathrm{m}^{2}$ ) and ten type 2 diabetic (age: $65 \pm 7$ years; sex: four men, six women; BMI: $26.7 \pm 2.3 \mathrm{~kg} / \mathrm{m}^{2}$; known duration of diabetes: 3-15 years; pharmacological treatment: metformin alone in five patients, metformin plus sulfonylurea in three patients, insulin in two patients) individuals. Non-diabetic donors had no history of diabetes; the mean plasma glucose value during their intensive care unit stay was $8.0 \pm 1.9 \mathrm{mmol} / \mathrm{l}$ (range: $4.9-10.6 \mathrm{mmol} / \mathrm{l}$ ) and the mean fructosamine concentration was $244 \pm 23 \mu \mathrm{mol} / 1$ (range: $211-277 \mu \mathrm{mol} / \mathrm{l}$ ). Islet preparations from three independent pancreases of non-diabetic donors (age: $65 \pm 4$ years; sex: one man, two women; BMI: $25.3 \pm 1.9 \mathrm{~kg} / \mathrm{m}^{2}$ ) were also studied in selected experiments (see below).

Immunocytochemistry and electron microscopy Samples were taken at the level of the pancreatic neck to perform immunocytochemistry $[10,11]$ and electron microscopy (EM) [12] evaluations. For immunocytochemistry, sequential $4 \mu \mathrm{m}$ sections were stained for insulin (guinea pig anti-insulin antibody, 1:100; Invitrogen, Carlsbad, CA, USA), glucagon (polyclonal rabbit anti-human glucagon antibody, 1:3,000 (Dako, Carpinteria, CA, USA) and chromogranin A (mouse monoclonal anti-chromogranin A antibody, $1 \mu \mathrm{g} / \mathrm{ml}$; Ventana, Oro Valley, AZ, USA). The anti-insulin and the anti-glucagon primary antibodies were also tested at 1:50, 1:200 and 1:300, and at 1:1,000, 1:2,000 and 1:4,000 dilution, respectively, and the working dilution was chosen based on the balance between signal intensity and non-specific background staining (electronic supplementary material [ESM] Fig. 1). Biotinylated secondary antibody, which reacts with mouse, rabbit, guinea pig and rat primary antibodies, was purchased as HistostainPlus kits (Invitrogen).

Morphometric analysis was performed by measuring insulin, glucagon and chromogranin A areas in the whole pancreatic tissue sections and in the islets (more than four insulin-positive cells). Since the weight of pancreas specimens was not known, mass values (pancreatic weight $\times$ fractional area positive for a given hormone) could not be determined and, in line with previous studies in humans $[10,11]$, the measurement of area was used as surrogate marker for cell mass. To perform islet count, the entire pancreatic sections were imaged using a Leica DM5500B microscope (Leica, Wetzlar, Germany) equipped with a motorised stage $\times 50$ magnification ( $\times 5$ objective lens). A tile image of the pancreatic section was generated by using Leica MetaMorph AF software, version 1.8, counts were performed and, in the case of borderline sizes, were confirmed at a magnification of $\times 400(\times 40$ objective lens; to discriminate between islets and clusters). The areas of islets and clusters stained positive for insulin, glucagon or chromogranin A were manually delimited by the operators at a magnification of $\times 400$ by the use of the Trace Region Leica tool, values were obtained through the Region Measurement tool and calculations finally performed by Excel Office suite (Microsoft, Redmond, WA, USA) to determine the fractional areas. EM assessment [12] was performed on 5,311 islet cells in total to evaluate the proportion of beta cells; insulin granules morphometric analysis was performed with 661 beta cells in non-diabetic and 598 beta cells in diabetic samples.

Islet isolation and functional studies Isolated islets were prepared as described previously $[12,13]$, and insulin secretion determined by batch incubation $(45 \mathrm{~min})$ in response to 3.3 and $16.7 \mathrm{mmol} / 1$ glucose [12]. In addition, morphological, functional and ultra-structural studies were performed with islets from three independent non-diabetic donors after $24 \mathrm{~h}$ incubation with $22.2 \mathrm{mmol} / \mathrm{l}$ glucose.

Statistical analysis: Results are expressed as mean \pm SD. Differences between groups were assessed by the two-tailed or paired Student's $t$ test, as appropriate.

\section{Results}

The area of the pancreatic sections ranged from 63.1 to $139.2 \mathrm{~mm}^{2}$. In accordance with previous studies [13, 14], light microscopy revealed that the islets varied in terms of size, insulin- and glucagon-positive areas, and they either retained a normal architecture or instead displayed sparse architecture (ESM Fig. 2). Overall, the number of islets trended lower in diabetic $\left(10.9 \pm 2.6\right.$ per $\left.10 \mathrm{~mm}^{2}\right)$ compared with non-diabetic $\left(14.4 \pm 11.5\right.$ per $\left.10 \mathrm{~mm}^{2}\right)$ samples. Average islet diameter did not differ between diabetic $(101.4 \pm 42.0 \mu \mathrm{m})$ and non-diabetic $(108.2 \pm 48.7 \mu \mathrm{m})$ samples. Fractional pancreatic insulinpositive area $(0.47 \pm 0.13 \%$ vs $1.02 \pm 0.43)$ and fractional islet insulin-positive area $(54.9 \pm 6.3 \%$ vs $72.1 \pm 8.7 \%$, see representative images in Fig. 1a, e), were significantly lower (both $p<0.01)$ in type 2 diabetic samples. Altogether, although obtained from a relatively small number of samples, these results largely confirm previous work reporting a decreased amount of beta cells in type 2 diabetes [2-6]. However, the main aim of the present study was to evaluate if this apparent 


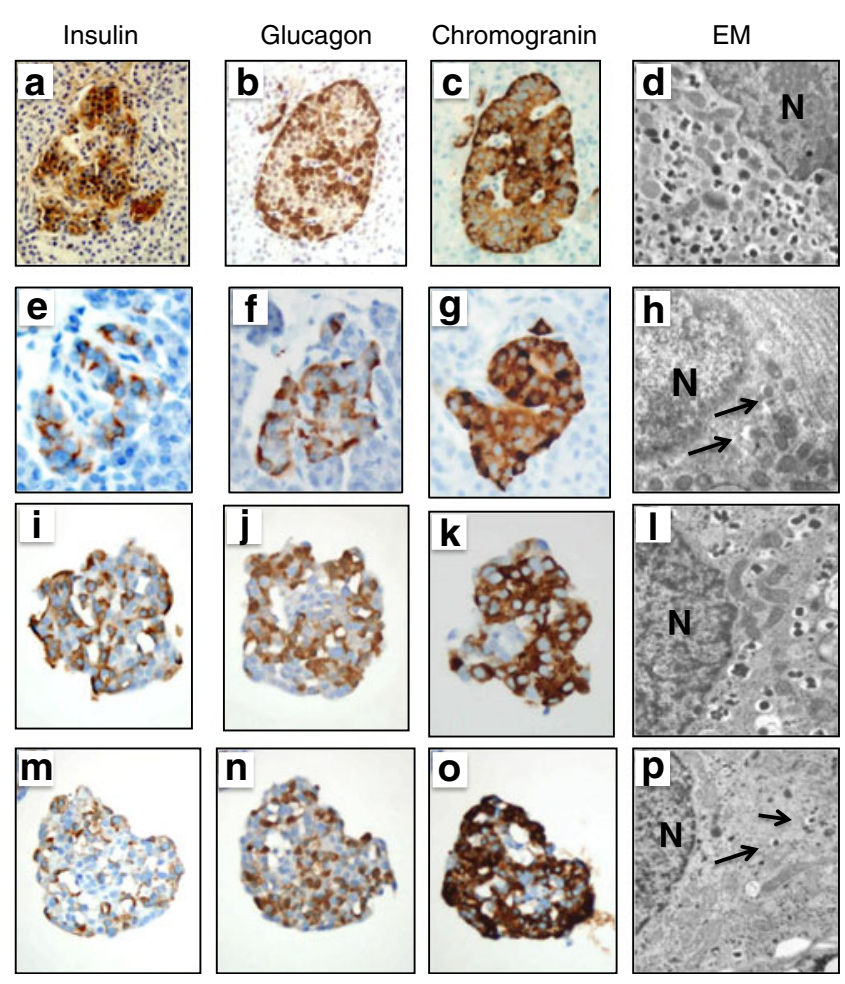

Fig. 1 Representative images of insulin, glucagon and chromogranin A immunostaining in: non-diabetic islet cells $(\mathbf{a}, \mathbf{b}$ and $\mathbf{c})$; type 2 diabetic islet cells (e, f and $\mathbf{g}$ ); non-diabetic islet cells pre-exposed to normal glucose $(5.5 \mathrm{mmol} / \mathrm{l})(\mathbf{i}, \mathbf{j}$ and $\mathbf{k})$; non-diabetic islet cells pre-exposed to high glucose $(22.2 \mathrm{mmol} / \mathrm{l})(\mathbf{m}, \mathbf{n}$ and $\mathbf{o})$. Representative electron microscopy (EM) images of a non-diabetic normal beta cell (d), a type 2 diabetic beta cell (h), a non-diabetic beta cell pre-exposed to normal glucose (I) and a non-diabetic beta cell pre-exposed to high glucose (p); note the low number of insulin granules (arrows) in $\mathrm{h}$ and $\mathrm{p}$. $\mathrm{N}$, nucleus

loss of beta cells may be overestimated. Indeed, when beta cells were counted by EM (Fig. 1d, h), the approximately $10 \%$ decrease in type 2 diabetic specimens $(63.0 \pm 8.6 \%$ vs $70.1 \pm 6.4 \%)$ was barely significant ( $p=0.051)$. In addition, beta cell proportion as measured by light and EM differed significantly in samples from the diabetic $(p=0.027)$ but not from the non-diabetic $(p=0.56)$ group. There were significantly $(p<0.01)$ fewer insulin granules (Fig. $1 \mathrm{~d}, \mathrm{~h})$ in diabetic beta cells $(3.1 \pm 0.2$ vs $5.6 \pm 0.3 \mathrm{ml} \%)$. Glucagon-containing cells (Fig. 1b, f) were similarly represented in non-diabetic (light microscopy: $20.2 \pm 5.3 \%$; EM: $21.3 \pm 6.6 \%$ ) and diabetic $(23.3 \pm 5.4 \%$ and $21.6 \pm 6.9 \%)$ samples. Intriguingly, chromogranin A (a marker of endocrine cells) expression was detected in a similar proportion of non-diabetic $(89.0 \pm 5.5 \%)$ and type 2 diabetic $(86.4 \pm 6.1 \%)$ islets, including cells negative for insulin (Fig. 1c, g).

When isolated non-diabetic islets were studied, $24 \mathrm{~h}$ exposure to high glucose reduced the insulin-positive area as assessed by light microscopy (Fig. 1i, m) (treated vs untreated: $49 \pm 11 \%$ vs $74 \pm 8 \% ; p=0.03$ ) but not as assessed by EM $(67 \pm 5 \%$ vs $71 \pm 7 \% ; p=0.5)$ (Fig. 11, p). A marked reduction in insulin granules (Fig. 1p) was observed in beta cells from islets exposed to high-glucose. There was no change in glucagon staining (Fig. 1j, n) or chromogranin A staining (Fig. 1k, o) in response to high glucose exposure.

Insulin release (pmol/islet/min) at $3.3 \mathrm{mmol} / \mathrm{l}$ glucose did not differ significantly between ND $(0.21 \pm 0.07)$ and type 2 diabetic $(0.19 \pm 0.06)$ islets. However, insulin secretion at $16.7 \mathrm{mmol} / 1$ glucose was $\sim 50 \%$ lower from the diabetic cells $(0.24 \pm 0.03$ vs $0.52 \pm 0.33, p=0.04)$; after pre-culture with high glucose, a decrease in glucose-stimulated insulin release $(0.28 \pm 0.15$ vs $0.61 \pm 0.13, p=0.04)$ was found, similar to that of type 2 diabetic islets.

\section{Conclusions}

Previous work has unequivocably revealed that the beta cell amount in human type 2 diabetes is reduced, mainly due to increased apoptosis, and the implications of this have been widely discussed $[2-6,15,16]$. In addition, in carefully performed examinations, morphological variations in type 2 diabetic islets have also been reported [13, 14]. The present study confirms the presence of such alterations by the use of insulin immunocytochemistry and the measurement of fractional pancreatic beta cell area (a surrogate of beta cell mass) [10]. More importantly, our results, based on parallel light and electron microscopy examinations of pancreatic samples from nondiabetic and diabetic donors, suggest that a proportion of beta cells in type 2 diabetic islets may not be detectable by standard immunohistochemistry staining, possibly due to insulin degranulation, potentially leading to an overestimation of beta cell loss, in at least some type 2 diabetic pancreases or islets. However, we confirmed the marked loss of glucose-stimulated insulin secretion function in type 2 diabetic islets [7, 17]. Interestingly, these results were largely mimicked by preexposure of non-diabetic islets to high glucose concentrations. Although the experimental condition we used ( $24 \mathrm{~h}$ incubation at $22.2 \mathrm{mmol} / 1$ glucose) is a simplistic attempt to reproduce what may happen to the beta cells in clinical diabetes, by doing so we were nevertheless able to show that the beta cell count was decreased as assessed by insulin staining but not as assessed by EM examination, and glucose-stimulated insulin secretion was blunted. This indicates that glucose-stimulated insulin secretion from human islets may be reduced without an actual loss of beta cells.

Although a relatively low number of pancreases were included in our study, the results are overall in agreement with recent work showing that changes in beta cell phenotype, including de-differentiation [9], may contribute to beta cell failure in type 2 diabetes in addition to apoptosis. On the whole, these findings support the concept that rescuing a beta cell functional phenotype could represent a major focus in the treatment of type 2 diabetic patients. 
Funding This work was supported by the Innovative Medicine Initiative Joint Undertaking under grant agreement no. 155005 (IMIDIA), resources of which are composed of financial contribution from the European Union's Seventh Framework Programme (FP7/2007-2013) and EFPIA companies in kind contribution, and by the Italian Ministry of University and Research (PRIN 2010-2012).

Duality of interest The authors declare that there is no duality of interest associated with this manuscript.

Contribution statement LM, MM and PM were involved in the conception and design of the study; LM, MS, MM, DC, MB, FSy, LM, DF, $\mathrm{FSc}, \mathrm{FO}, \mathrm{FF}, \mathrm{UB}$ and $\mathrm{PM}$ were involved in the acquisition, analysis and interpretation of data; PMas was involved in the interpretation of data; LM and PM drafted the article; MS, MM, DC, MB, FSy, LM, DF, FSc, FO, FF, PMas and UB critically revised the article; all authors gave final approval of the version to be published.

\section{References}

1. Inzucchi SE, Bergenstal RM, Buse JB et al (2012) Management of hyperglycaemia in type 2 diabetes: a patient-centered approach. Position statement of the American Diabetes Association (ADA) and the European Association for the Study of Diabetes (EASD). Diabetologia 55:1577-1596

2. Meier JJ (2008) Beta cell mass in diabetes: a realistic therapeutic target? Diabetologia 51:703-713

3. Ahrén B (2005) Type 2 diabetes, insulin secretion and beta-cell mass. Curr Mol Med 5:275-286

4. Hanley NA, Hanley KP, Miettinen PJ, Otonkoski T (2008) Weighing up beta-cell mass in mice and humans: self-renewal, progenitors or stem cells? Mol Cell Endocrinol 288:79-85
5. Donath MY, Halban PA (2004) Decreased beta-cell mass in diabetes: significance, mechanisms and therapeutic implications. Diabetologia 47:581-589

6. Butler AE, Janson J, Bonner-Weir S, Ritzel R, Rizza RA, Butler PC (2003) Beta cell deficit and increased beta cell apoptosis in humans with type 2 diabetes. Diabetes 52:102-110

7. Marchetti P, Lupi R, del Guerra S et al (2009) Goals of treatment for type 2 diabetes: beta-cell preservation for glycemic control. Diabetes Care 32(Suppl 2):S178-S183

8. Bradley D, Magkos F, Klein S (2012) Effects of bariatric surgery on glucose homeostasis and type 2 diabetes. Gastroenterology 143:897-912

9. Talchai C, Xuan S, Lin HV, Sussel L, Accili D (2012) Pancreatic beta cell dedifferentiation as a mechanism of diabetic beta cell failure. Cell 150:1223-1234

10. Meier JJ, Breuer TG, Bonadonna RC et al (2012) Pancreatic diabetes manifests when beta cell area declines by approximately $65 \%$ in humans. Diabetologia 55:1346-1354

11. Tancredi M, Marselli L, Lencioni C et al (2011) Histopathology and ex vivo insulin secretion of pancreatic islets in gestational diabetes: a case report. Islets 3:231-233

12. Marchetti P, Bugliani M, Lupi R et al (2007) The endoplasmic reticulum in pancreatic beta cells of type 2 diabetes patients. Diabetologia 50:2486-2494

13. Marselli L, Thorne J, Dahiya S et al (2010) Gene expression profiles of beta-cell enriched tissue obtained by laser capture microdissection from subjects with type 2 diabetes. PLoS One 5:e11499

14. Kilimnik G, Zhao B, Jo J et al (2011) Altered islet composition and disproportionate loss of large islets in patients with type 2 diabetes. PLoS One 6:e27445

15. Rahier J, Guiot Y, Goebbels RM, Sempoux C, Henquin JC (2008) Pancreatic beta-cell mass in European subjects with type 2 diabetes. Diab Obes Metab 10(Suppl 4):32-34

16. Hanley AC, Austin E, Assouline-Thomas B et al (2010) Beta cell mass dynamics and islet cell plasticity in human type 2 diabetes. Endocrinology 151:1462-1472

17. Deng S, Vatamaniuk M, Huang X et al (2004) Structural and functional abnormalities in the islets isolated from type 2 diabetic subjects. Diabetes 53:624-632 